\title{
Numerical Simulation for a Three-Dimensional Air Pollution Measurement Model in a Heavy Traffic Area under the Bangkok Sky Train Platform
}

\author{
Kewalee Suebyat $\mathbb{D}^{1,2}$ and Nopparat Pochai $\mathbb{D}^{1,2}$ \\ ${ }^{1}$ Department of Mathematics, Faculty of Science, King Mongkut's Institute of Technology Ladkrabang, Bangkok 10520, Thailand \\ ${ }^{2}$ Centre of Excellence in Mathematics, Commission on Higher Education (CHE), Si Ayutthaya Road, Bangkok 10400, Thailand \\ Correspondence should be addressed to Nopparat Pochai; nop_math@yahoo.com
}

Received 10 October 2017; Accepted 1 February 2018; Published 5 March 2018

Academic Editor: Felix Sadyrbaev

Copyright (c) 2018 Kewalee Suebyat and Nopparat Pochai. This is an open access article distributed under the Creative Commons Attribution License, which permits unrestricted use, distribution, and reproduction in any medium, provided the original work is properly cited.

\begin{abstract}
Air pollutant levels in Bangkok are generally high in street tunnels. They are particularly elevated in almost closed street tunnels such as an area under the Bangkok sky train platform with high traffic volume where dispersion is limited. There are no air quality measurement stations in the vicinity, while the human population is high. In this research, the numerical simulation is used to measure the air pollutant levels. The three-dimensional air pollution measurement model in a heavy traffic area under the Bangkok sky train platform is proposed. The finite difference techniques are employed to approximate the modelled solutions. The vehicle air pollutant emission due to the high traffic volume is mathematically assumed by the pollutant sources term. The simulation is also considered in averaged and moving pollutant sources due to manner vehicle emission. The proposed approximated air pollutant concentration indicators can be replaced by user required gaseous pollutants indices such as NOx, SO2, CO, and PM2.5.
\end{abstract}

\section{Introduction}

Nowadays if we are talking about pollution, surely one of the pollution sources that we face and have a big effect on society is "air pollution." Air pollution does not only affect one society but also the problem for human life and environment that everyone all over the world should realize. Air pollution is harmful to human health because it releases pollutants and dirty air which caused asthma, lungs, and cancer. Moreover, it is a major factor which affects environmental resources as well as human-made structures and facilities and contributes to climate change.

Sources of air pollution can be classified into two types which are natural sources and artificial sources. Natural sources of pollution come from natural phenomena such as volcanic eruptions, forest fires, biological decay, pollen grains, marshes, and radioactive materials. On the other hand, artificial sources are those created by human beings such as thermal power plants, vehicular emissions, fossil fuel burning, and agricultural activities. Air pollution can occur in many forms but in general it occurs in the form gas and particulate contaminants which are in our atmosphere. Gaseous pollutants include carbon monoxide (CO), nitrogen oxides (NOx), sulfur dioxide (SO2), ozone (O3), and various gaseous.

Some people might wonder if indoor or outdoor air is more polluted. According to studies of scientists, indoor air pollution is often more harmful than outdoor air pollution, especially because we spend most of the time per day indoor inside our home or office. The air inside our homes and offices can sometimes be much more polluted compared to outdoor air and thus presents a major health threat. In their latest study, the British scientists measured air quality inside and outside three residential buildings with different types of energy use. What they found was that the levels of one of the most common air pollutants, nitrogen dioxide (NO2), in kitchens in the city center apartments with gas cookers were as much as three times higher than the levels measured outdoors and well above clean air quality standards. 
In [1], also in October 2016, more than 140 countries reached an agreement to reduce the use of these chemicals which are used in air conditioners and refrigerators and to find greener alternatives over time. David Doniger, director of NRDC's Climate and Clean Air program, wrote, "NRDC estimates that the agreed HFC phase-down will avoid the equivalent of more than 80 billion tons of $\mathrm{CO} 2$ over the next 35 years." Moreover, Walke said, "make good choices about transportation. When you can walk, ride a bike, or take public transportation. For driving, choose cars that get better miles per gallon of gas or choose an electric car." The sources of smog and soot are similar. Walke said, "both come from cars and trucks, factories, power plants, incinerators, engines." So, a wise decision is encouraged to make our world green.

In 1961, [2] studied the pollution of the air (smoke, polycyclic hydrocarbons, carbon monoxide, and lead) by motor vehicles in two London road tunnels. It was found that the concentration of air pollution in the tunnels does not appear to be high but the effect of traffic on the concentration of smoke, polycyclic hydrocarbons, carbon monoxide, and lead in the air of city streets deserves continued study. In 2002, [3] studied average air pollutant concentration during weekdays and found it to be higher than during the weekend. The test result showed that the average air pollutant concentrations for the three urban sites are noticeably higher than the suburban site. Our analysis revealed that an obvious way to reduce the build-up of pollutant concentration on Bangkok streets would be to speed up the flow of traffic and prevent long periods of idling in congested streets. In 2004, [4] studied the stability conditions for several different numerical techniques which were developed and compared for solving the three-dimensional advection-diffusion equation with constant coefficient. The results of a numerical experiment were presented, and the accuracy and central processor time needed were discussed and compared. In 2006, [5] studied the numerical methods for solving the advectiondiffusion equation. It was solved by using cubic splines to estimate first and second derivatives and also by solving the same problem using two standard finite difference schemes (the FTCS and Crank-Nicolson methods). The numerical results were compared with analytical solutions. It was found that, for the examples studied, the finite difference methods yielded better pointwise solutions than the spline methods. In 2016, [6] studied the three-dimensional air quality model. The considered domain was divided into two zones: a factory zone and a residential zone. The modifications of the atmospheric stability classes and wind velocities from multiple point sources were also analyzed by using the threedimensional fractional step method. In 2017, [7] studied a three-dimensional advection-diffusion equation by using the explicit forward difference method. The wind inflows are considered in two cases: there is wind inflow only in $x$ direction and there are wind inflow in $x$-direction and $y$ direction. Moreover, we added the obstacles along the middle into the tunnel. The results of the model are satisfactory.

Currently in Bangkok, Thailand, air pollution from car exhaust on the street, which contains particulates, especially from old cars or diesel cars, is harmful to people's health. Scientists are concerned that the particulates carrying toxic chemicals, such as nitrous oxide and carbon monoxide, when deeply in haled, can be harmful to people's health. Bangkok Transit System (BTS) provides an effective route of urban transport for Bangkok people because BTS facilitates speed and convenience for transportation. The major source of air pollution under Bangkok sky train platform comes from vehicle exhaust, mobile source, and others sources including smoke from restaurants, construction, and building demolition. Therefore, it is also causing some of the environmental impacts, especially the air pollutant impact to the vicinity area around its platform with high traffic and large amount of people.

These days, an increasing in population caused heavy traffic and air pollution on the road. Air pollution around the platform in an area under BTS platform has increased dramatically. So, if we know the value of the concentration of pollution that is likely to occur from the existing pollution accumulation or may be from sources of emissions, such as from car smoke, we might be able to control the concentration of air pollution in that area not to exceed the standard. As already mentioned, we recognized the importance of air pollution. Therefore, the purpose of this research is to approximate the concentration of air pollutant in the area under the Bangkok sky train platform with moving air pollutant sources by heavy traffic of vehicles in different time by using the finite difference technique. It can help control the pollutant from the traffic and crowded people in this area. It will be beneficial to human and environment. However, this area should be implemented into the wind inflow directions near the tunnel because it affects the concentration of air pollutant. Then the wind inflow directions are an important factor of the model. So, we distinguish two cases: there is wind inflow only in $x$-direction and there is wind inflow in $x$ - and $y$-directions.

\section{Governing Equation}

A street tunnel is a place for foot or vehicular road traffic, where the street is flanked by buildings on both sides, including the top area that is also closed. The street tunnel configuration is shown in Figure 1. An overhead part of the street is the sky train platform and both sides of the street are composed of sections of building. In this research, the simulation of configuration of street tunnel is divided into two cases.

Case 1. Assume that the wind is flowing only in $x$-direction. The considered street tunnel is illustrated in Figure 2(a). The wind direction field is shown in Figure 2(b).

Case 2. Assume that the wind is flowing in $x$ - and $y$ directions. The considered street tunnel is illustrated in Figure 3(a). The wind direction field is shown in Figure 3(b).

The considered domain is restricted by $\Omega=\{(x, y$, $z) ; 0 \leq x \leq L, 0 \leq y \leq W, 0 \leq z \leq H\}$, where $W$ is the platform width (m), $L$ is the platform length (m), and $H$ is the platform height $(\mathrm{m})$ over the street tunnel. 


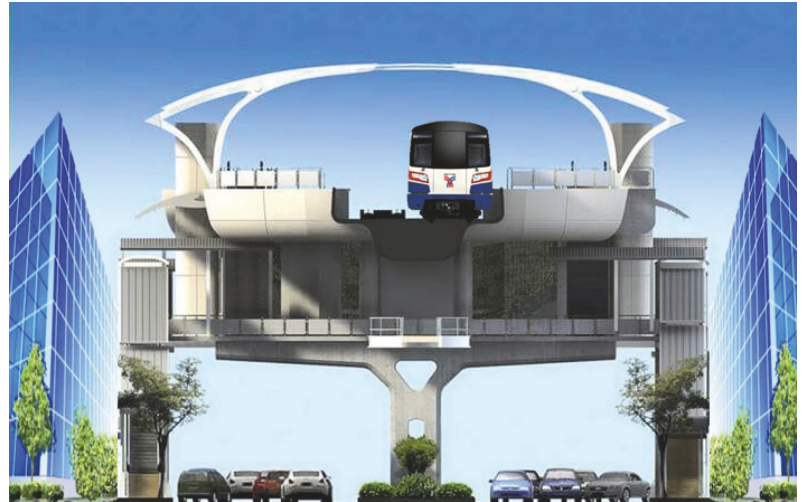

FIGURE 1: The street tunnel configuration.

The air pollutant concentration can be described by a threedimensional advection-diffusion equation as follows:

$$
\frac{\partial C}{\partial t}+V \cdot \nabla C=\nabla \cdot(\bar{K} \otimes \nabla C)+R(x, y, z, t),
$$

where $C=C(x, y, z, t)$ is the air pollutant concentration at point $(x, y, z)$ in Cartesian coordinates and at time $t\left(\mathrm{~kg} / \mathrm{m}^{3}\right)$. The vector $V$ is the wind velocity field $(\mathrm{m} / \mathrm{sec})$; $\bar{K}$ is the eddy-diffusivity or dispersion tensor $\left(\mathrm{m}^{2} / \mathrm{sec}\right) \cdot \nabla=$ $(\partial / \partial x) \vec{i}+(\partial / \partial y) \vec{j}+(\partial / \partial z) \vec{k}, \otimes$ is matrix multiplication, and $R(x, y, z, t)$ describes sources or sinks of air pollutants $\left(\sec ^{-1}\right)$.

If the wind velocity and diffusion coefficient of pollutant are constant, the governing equation becomes

$$
\begin{aligned}
\frac{\partial C}{\partial t} & +u \frac{\partial C}{\partial x}+v \frac{\partial C}{\partial y}+w \frac{\partial C}{\partial z} \\
& =k_{x} \frac{\partial^{2} C}{\partial x^{2}}+k_{y} \frac{\partial^{2} C}{\partial y^{2}}+k_{z} \frac{\partial^{2} C}{\partial z^{2}}+R(x, y, z, t),
\end{aligned}
$$

where $u, v$, and $w$ are the constant wind velocity $(\mathrm{m} / \mathrm{sec})$ in $x, y$, and $z$-directions, respectively, and $k_{x}, k_{y}$, and $k_{z}$ are the constant diffusion coefficient $\left(\mathrm{m}^{2} / \mathrm{sec}\right)$ in $x, y$, and $z$ directions, respectively.

By the assumption, we assumed that the wind inflow is along the horizontal direction and the dispersion is horizontally isotropic. Consequently, the three-dimensional advection-diffusion equation in (2) can be written as

$$
\begin{aligned}
\frac{\partial C}{\partial t}+u \frac{\partial C}{\partial x}+v \frac{\partial C}{\partial y}= & k_{h} \frac{\partial^{2} C}{\partial x^{2}}+k_{h} \frac{\partial^{2} C}{\partial y^{2}}+k_{v} \frac{\partial^{2} C}{\partial z^{2}} \\
& +R(x, y, z, t),
\end{aligned}
$$

where $k_{h}$ is a constant dispersion coefficient in the horizontal direction $\left(\mathrm{m}^{2} / \mathrm{sec}\right)$ and $k_{v}$ is a constant dispersion coefficient in the $z$-direction (vertical) $\left(\mathrm{m}^{2} / \mathrm{sec}\right)$ with the appropriate initial and boundary conditions.

We consider the components of the tunnel in Figure 4 and the model of the problem is divided into three zones as shown in Figure 5. The potential air pollutant concentration can be described by $C(x, y, z, 0)=f(x, y, z)$, for all $(x, y, z) \in \Omega$. The boundary conditions are as follows:

$$
\begin{aligned}
& \text { Entrance gate: } C(0, y, z, t)=c_{N_{1}}, 0<y<W, 0< \\
& z<H . \\
& \text { Margin of entrance gate: }(\partial C / \partial x)(0, y, z, t)= \\
& c_{N_{2}}, y=0, W, z=0, H . \\
& \text { Exit gate: }(\partial C / \partial x)(L, y, z, t)=c_{X} . \\
& \text { Both side walls: }(\partial C / \partial y)(x, 0, z, t) \\
& c_{W_{1}},(\partial C / \partial y)(x, W, z, t)=c_{W_{2}} \cdot \\
& \text { Ground: }(\partial C / \partial z)(x, y, 0, t)=c_{F} . \\
& \text { Platform ceiling: }(\partial C / \partial z)(x, y, H, t)=c_{T}, A<y<B . \\
& \text { Ceiling parallel gaps: }(\partial C / \partial z)(x, y, H, t)=c_{G_{1}}, 0 \leq \\
& y \leq A,(\partial C / \partial z)(x, y, H, t)=c_{G_{2}}, B \leq y \leq W,
\end{aligned}
$$

where $c_{N_{1}}$ is the inflow air pollutant concentration at the entrance gate. $c_{N_{2}}, c_{X}, c_{W_{1}}, c_{W_{2}}, c_{F}, c_{T}, c_{G_{1}}, c_{G_{2}}$ are the average rate of change of air pollutant concentration at the margin of entrance gate, exit gate, both side walls, ground, platform ceiling, and both ceiling parallel gaps, respectively. $A$ is the distance from the right wall to the right-ended platform ceiling; see in Figure 5. $B$ is also the distance from the right wall to the left-ended platform ceiling; see in Figure 5.

\section{Numerical Techniques}

The finite difference method is used to approximate the solutions to the governing equation. The domain $\Omega$ is divided by $x_{i}=i \Delta x, i=0,1,2, \ldots, M ; y_{j}=j \Delta y, j=0,1,2, \ldots$, $N ; z_{k}=k \Delta z, k=0,1,2, \ldots, P ; t_{n}=n \Delta t, n=$ $0,1,2, \ldots, Q$ over three spaces and time coordinate axes, respectively. The approximated air pollutant concentration at point $(i \Delta x, j \Delta y, k \Delta z, n \Delta t)$ is denoted by $C_{i, j, k}^{n}=$ $C(i \Delta x, j \Delta y, k \Delta z, n \Delta t)$ at the grid point $(i, j, k, n)$. The constant spatial and temporal grid spacing are $\Delta x=L / M, \Delta y=$ $W / N, \Delta z=H / P, \Delta t=T / Q$, respectively.

In this research, an explicit forward time central space (FTCS) method is employed. Consequently, the finite difference equation to (3) becomes

$$
\begin{aligned}
& \frac{C_{i, j, k}^{n+1}-C_{i, j, k}^{n}}{\Delta t}+u\left(\frac{C_{i+1, j, k}^{n}-C_{i-1, j, k}^{n}}{2 \Delta x}\right) \\
& \quad+v\left(\frac{C_{i, j+1, k}^{n}-C_{i, j-1, k}^{n}}{2 \Delta y}\right) \\
& =D_{h}\left(\frac{C_{i+1, j, k}^{n}-2 C_{i, j, k}^{n}+C_{i-1, j, k}^{n}}{(\Delta x)^{2}}\right) \\
& \quad+D_{h}\left(\frac{C_{i, j+1, k}^{n}-2 C_{i, j, k}^{n}+C_{i, j-1, k}^{n}}{(\Delta y)^{2}}\right) \\
& +D_{v}\left(\frac{C_{i, j, k+1}^{n}-2 C_{i, j, k}^{n}+C_{i, j, k-1}^{n}}{(\Delta z)^{2}}\right)+(\Delta t) R_{i, j, k}^{n} .
\end{aligned}
$$




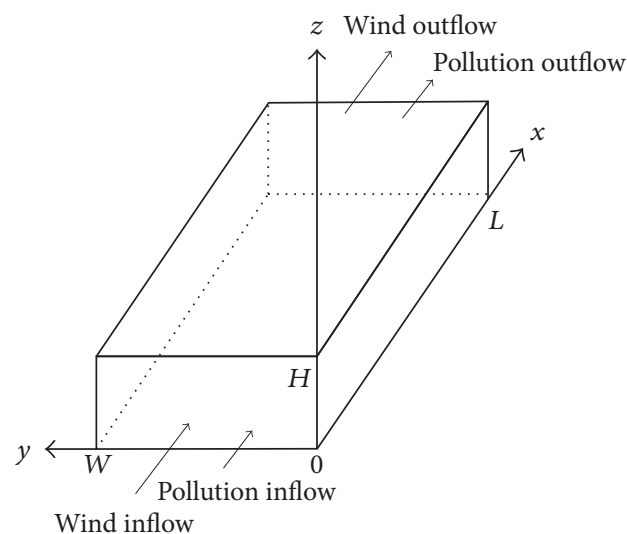

(a)

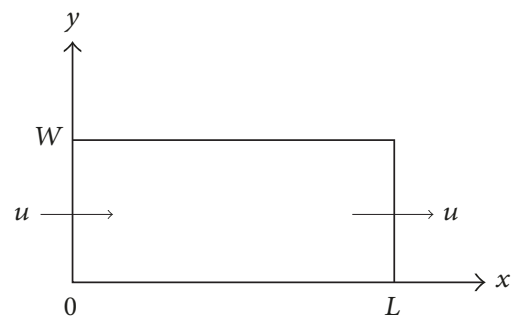

(b)

Figure 2: (a) The domain for street tunnel (Case 1). (b) The wind direction (Case 1).

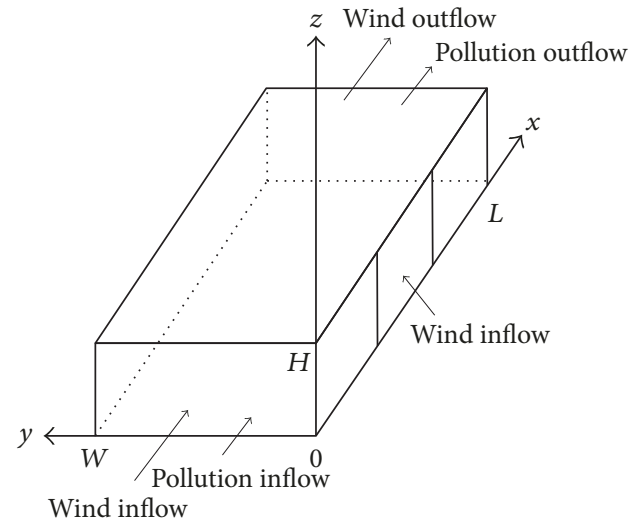

(a)

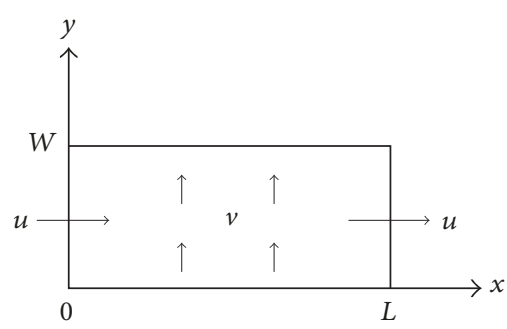

(b)

Figure 3: (a) The domain for street tunnel (Case 2). (b) The wind direction (Case 2).

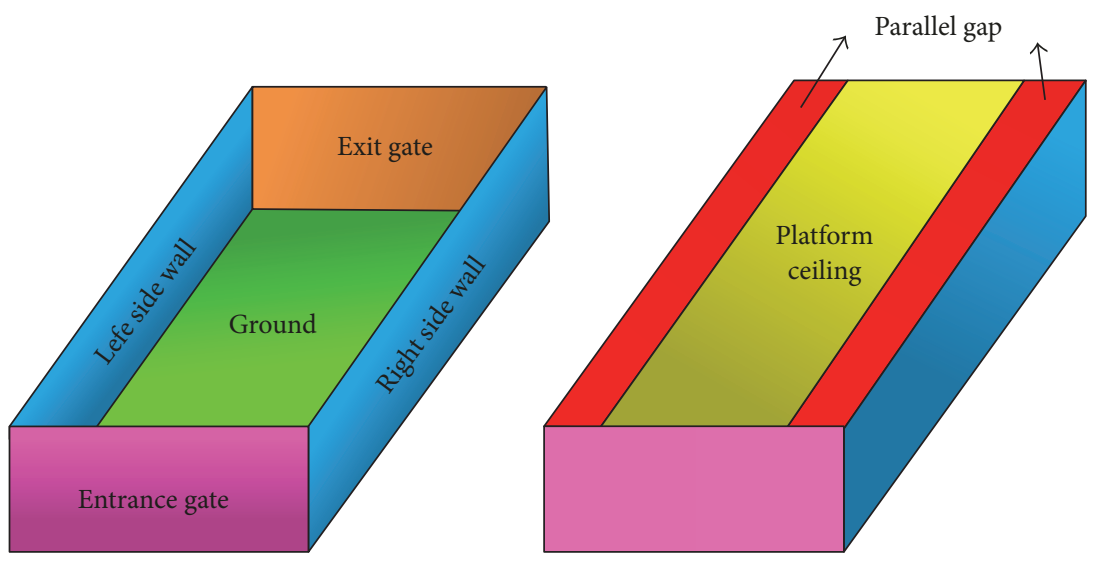

FIgURE 4: Components of the tunnel. 


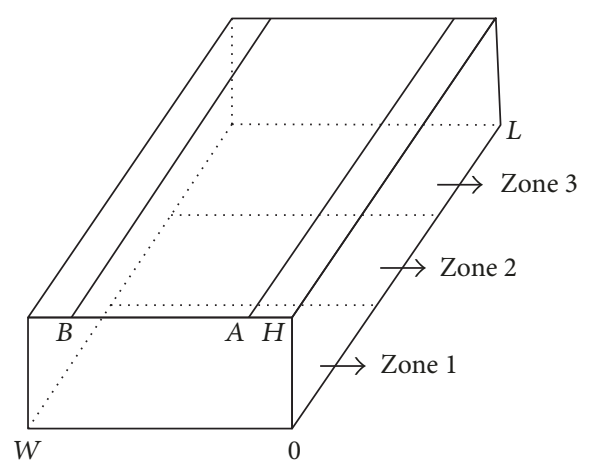

Figure 5: Model of the problem.

Rearrangement of (4) gives

$$
\begin{aligned}
C_{i, j, k}^{n+1}= & \left(s_{x}+\frac{r_{x}}{2}\right) C_{i-1, j, k}^{n}+\left(s_{y}+\frac{r_{y}}{2}\right) C_{i, j-1, k}^{n} \\
& +\left(s_{z}\right) C_{i, j, k-1}^{n}+\left(s_{x}-\frac{r_{x}}{2}\right) C_{i+1, j, k}^{n} \\
& +\left(s_{y}-\frac{r_{y}}{2}\right) C_{i, j+1, k}^{n}+\left(s_{z}\right) C_{i, j, k+1}^{n} \\
& +\left(1-2 s_{x}-2 s_{y}-2 s_{z}\right) C_{i, j, k}^{n}+(\Delta t) R_{i, j, k}^{n},
\end{aligned}
$$

in which $r_{x}=u \Delta t / \Delta x, r_{y}=v \Delta t / \Delta y, s_{x}=D_{h} \Delta t /(\Delta x)^{2}$, $s_{y}=D_{h} \Delta t /(\Delta y)^{2}$, and $s_{z}=D_{v} \Delta t /(\Delta z)^{2}$.

The stability condition of the proposed finite difference scheme, which can be investigated by using the von Neumann method $[4,8]$, is stable if both

$$
\begin{gathered}
s_{x}+s_{y}+s_{z} \leq \frac{1}{2} \\
\frac{r_{x}^{2}}{s_{x}}+\frac{r_{y}^{2}}{s_{y}} \leq 3,
\end{gathered}
$$

are satisfied.

The finite difference scheme for the left end and the right end of the fictitious points is as follows:

$$
\begin{aligned}
\frac{\partial C}{\partial x}\left(x_{0}, y_{j}, z_{k}, t_{n}\right) & \approx \frac{-3 C_{0, j, k}^{n}+4 C_{1, j, k}^{n}-C_{2, j, k}^{n}}{2 \Delta x}=c_{N_{2}}, \\
\frac{\partial C}{\partial y}\left(x_{i}, y_{0}, z_{k}, t_{n}\right) & \approx \frac{-3 C_{i, 0, k}^{n}+4 C_{i, 1, k}^{n}-C_{i, 2, k}^{n}}{2 \Delta y}=c_{W_{1}}, \\
\frac{\partial C}{\partial z}\left(x_{i}, y_{i}, z_{0}, t_{n}\right) & \approx \frac{-3 C_{i, j, 0}^{n}+4 C_{i, j, 1}^{n}-C_{i, j, 2}^{n}}{2 \Delta z}=c_{F}, \\
\frac{\partial C}{\partial x}\left(x_{M}, y_{j}, z_{k}, t_{n}\right) & \approx \frac{3 C_{M, j, k}^{n}-4 C_{M-1, j, k}^{n}+C_{M-2, j, k}^{n}}{2 \Delta x} \\
& =c_{X}, \\
\frac{\partial C}{\partial y}\left(x_{i}, y_{N}, z_{k}, t_{n}\right) & \approx \frac{3 C_{i, N, k}^{n}-4 C_{i, N-1, k}^{n}+C_{i, N-2, k}^{n}}{2 \Delta y} \\
& =c_{W_{2}},
\end{aligned}
$$

$$
\begin{aligned}
\frac{\partial C}{\partial z}\left(x_{i}, y_{j}, z_{P}, t_{n}\right) & \approx \frac{3 C_{i, j, P}^{n}-4 C_{i, j, P-1}^{n}+C_{i, j, P-2}^{n}}{2 \Delta z}=c_{T} \\
& =c_{G_{2}}=c_{G_{2}} .
\end{aligned}
$$

\section{Numerical Experiments}

In this section, there are three simulations of released air pollutant phenomena demonstrated by using the finite difference in (5). In all simulations, the air is flowing along the $x$-direction from the entrance to the exit gates. There are two parallel gaps along the celling; see Figures 1 and 4 . There is no potential ambient air pollution. There are two buildings that were bracing the areas as well; see Figures 1 and 4. All of building walls are nonabsorbing air pollution materials. Since there is no potential air pollution, the initial condition is assumed by $f(x, y, z)=0$.

For three cases, the experimented area has dimensions such that the length, width, and height are 192, 26, and 6 meters, respectively. Then, the simulated domain is defined by $\Omega=\{(x, y, z) ; 0 \leq x \leq 192,0 \leq y \leq 26,0 \leq z \leq 6\}$. We assume that $c_{N_{1}}=1, c_{W_{1}}=c_{W_{2}}=c_{F}=c_{T}=0$, $c_{X}=c_{G_{1}}=c_{G_{2}}=-0.01, A=4$, and $B=24$. When we consider the model of problem as shown in Figure 5, $0 \leq x<64$, $64 \leq x \leq 128$, and $128<x \leq 192$ are zones 1 , zones 2 , and zones 3, respectively. For the grid spacing, $\Delta x=\Delta y=\Delta z=$ $2 \mathrm{~m}, z=4 \mathrm{~m}$, and $\Delta t=0.06 \mathrm{~s}$, and for the time, $T=30 \mathrm{~s}$. We choose the diffusion coefficient in $x$ - and $z$-direction as 0.1592 and $0.05 \mathrm{~m}^{2} / \mathrm{sec}$, respectively, with diffusion coefficient in $x$ - and $y$-direction being equal. The wind velocity in $x$-and $y$-direction is 2.7778 and $0 \mathrm{~m} / \mathrm{sec}$, respectively.

Simulation $A$ (source or sink emissions are averaged). In this example, we consider two cases. In the first case, $R$ is the constant of source $(R>0)$, which are $0.001,0.004$, and $0.007 \mathrm{sec}^{-1}$. In the second case, $R$ is the constant of $\operatorname{sink}(R<$ $0)$, which are $-0.001,-0.004$, and $-0.007 \mathrm{sec}^{-1}$. The results of Simulation A are shown in Figures 6-11 and 22-23.

Simulation $B$ (source or sink emissions are moving). In this example, we consider two cases. In the first case, $R$ is the function of source and $\operatorname{sink}(R>0, R<0)$, that is, $0.001 \sin (x t), 0.003 \sin (x t)$, and $0.005 \sin (x t) \sec ^{-1}$. In the second case, $R$ is the function of source $(R>0)$, which are $0.001|\sin (x t)|, 0.003|\sin (x t)|$, and $0.005|\sin (x t)| \sec ^{-1}$. The results of Simulation B are shown in Figures 12-17 and 24.

Simulation $C$ (source or sink emissions are mixed). In this example, we divided $R$ into 3 zones. That is, $R_{1}, R_{2}$, and $R_{3}$ are sources of zone 1 , zone 2 , and zone 3 , respectively. We consider three cases when $R$ is the constant of source. In the first case, $R$ is little and gradually increases, which are $R_{1}=$ $0.01, R_{2}=0.03$, and $R_{3}=0.05 \mathrm{sec}^{-1}$. In the second case, $R$ is the highest at the middle zone, which is $R_{1}=0.03, R_{2}=0.05$, and $R_{3}=0.03 \mathrm{sec}^{-1}$. In the last case, $R$ in zone 1 is the highest and gradually decreases, which are $R_{1}=0.05, R_{2}=0.03$, and $R_{3}=0.01 \mathrm{sec}^{-1}$. The results of Simulation $\mathrm{C}$ are shown in Figures 18-21 and 25. 


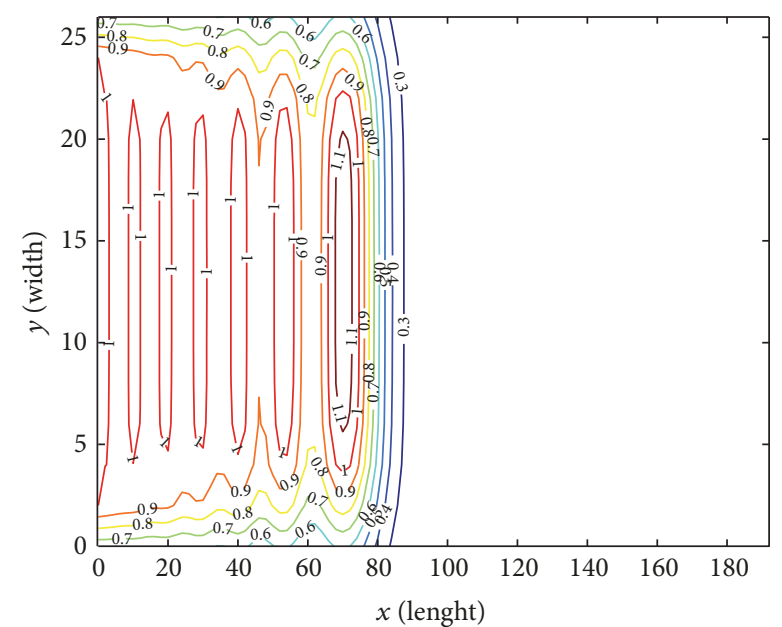

(6) Concentration of air pollutant

FIGURE 6: Contour plot of concentration of air pollutant levels for $R=0.007 \mathrm{sec}^{-1}$.

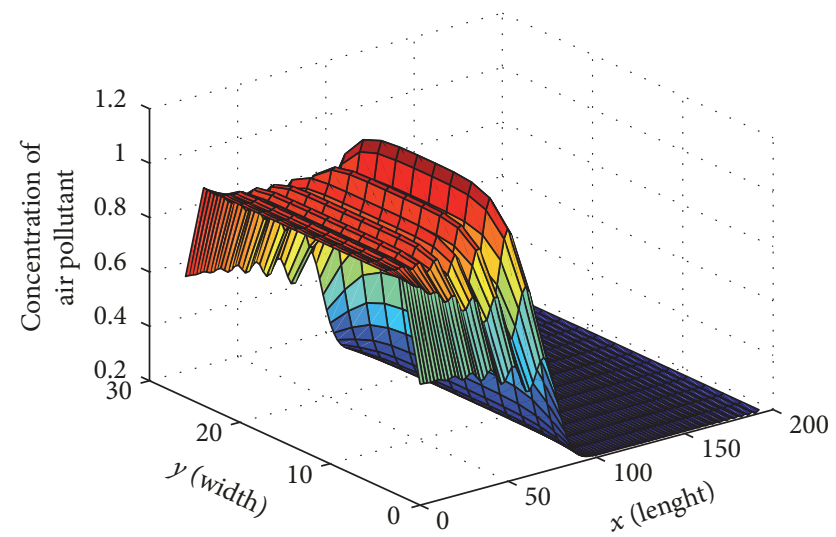

FIGURE 7: Surface plot of concentration of air pollutant levels for $R=0.007 \mathrm{sec}^{-1}$.

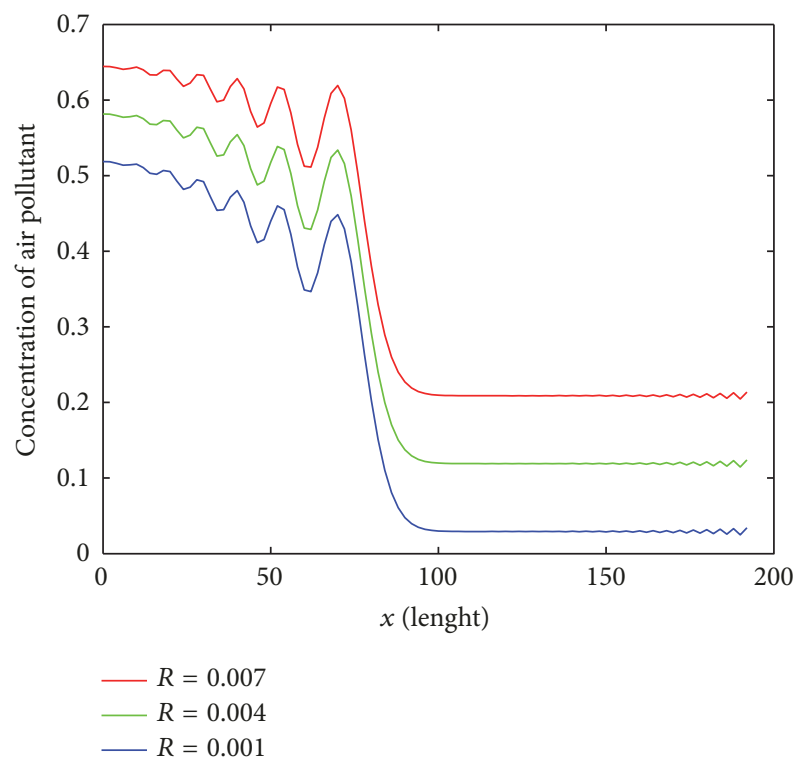

FIGURE 8: Compare the concentration of air pollutant where $R=$ $0.001, R=0.004$, and $R=0.007 \mathrm{sec}^{-1}$.

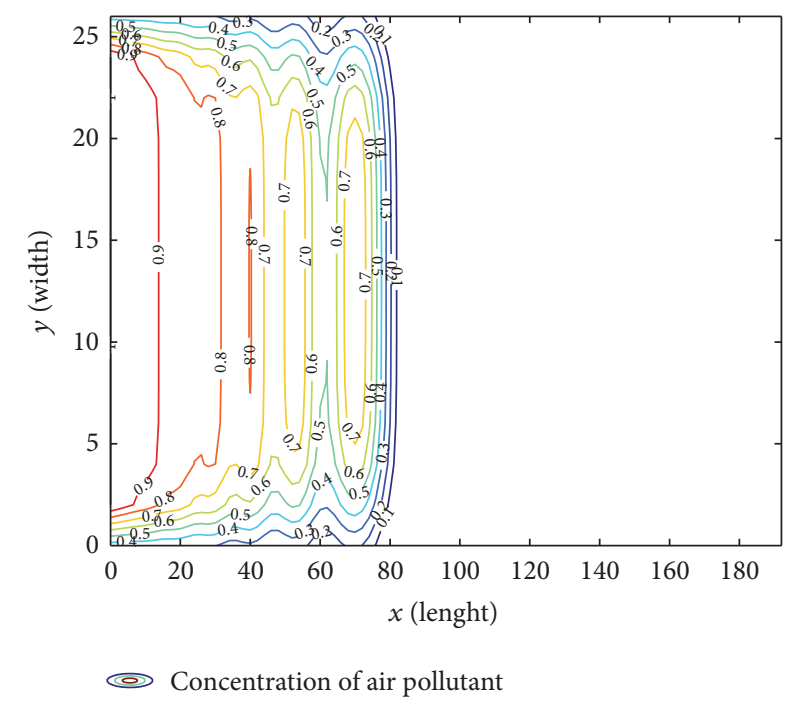

FIGURE 9: Contour plot of concentration of air pollutant levels for $R=-0.007 \mathrm{sec}^{-1}$.

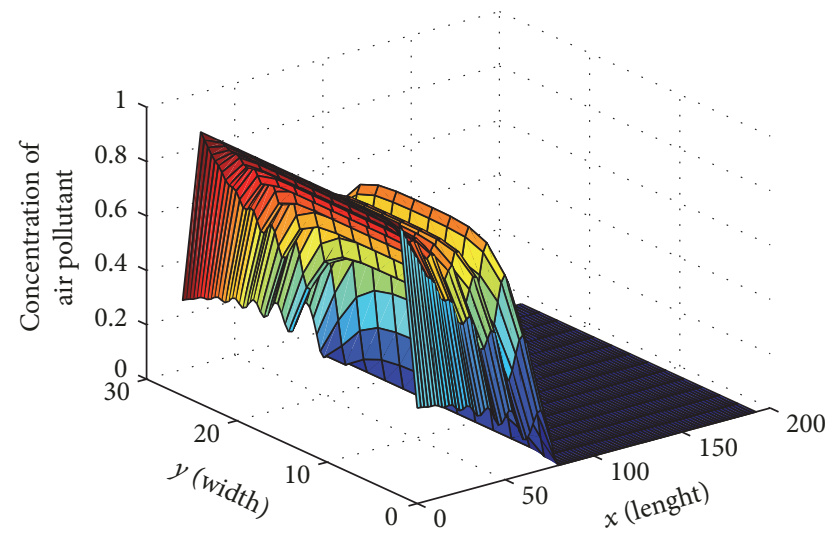

FIGURE 10: Surface plot of concentration of air pollutant levels for $R=-0.007 \mathrm{sec}^{-1}$.

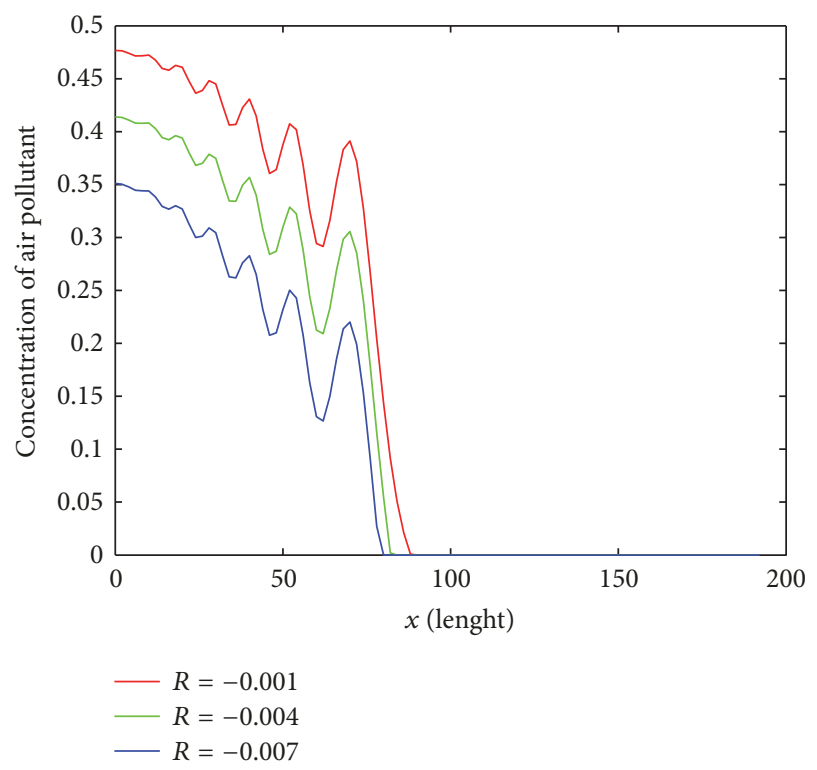

FIGURE 11: Compare the concentration of air pollutant where $R=$ $-0.001, R=-0.004$, and $R=-0.007 \mathrm{sec}^{-1}$. 


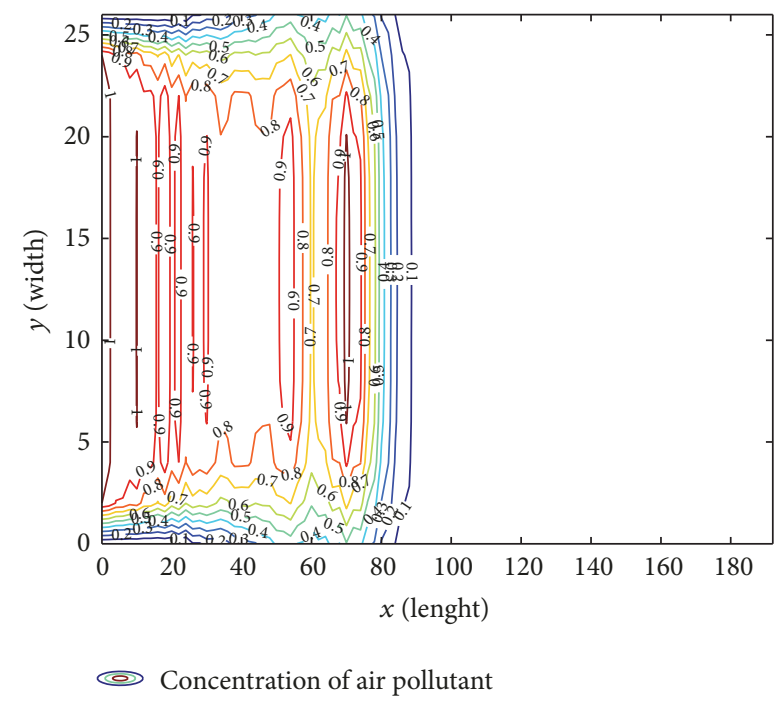

FIGURE 12: Contour plot of concentration of air pollutant levels for $R=0.001 \sin (x t) \sec ^{-1}$.

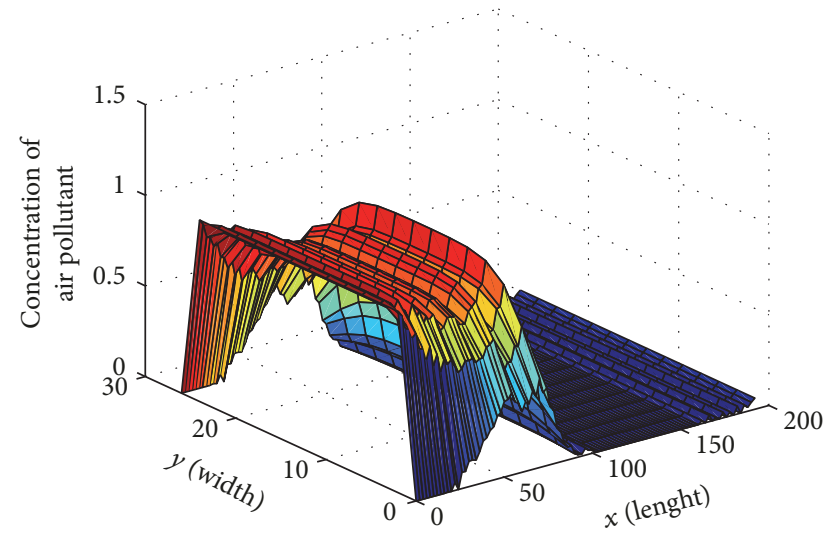

FIgURE 13: Surface plot of concentration of air pollutant levels for $R=0.001 \sin (x t) \sec ^{-1}$.

\section{Discussion}

The air pollutant concentrations are calculated by using a finite difference technique. Whether sources or sinks, it affected the air pollutant concentrations. The comparison of sources or sinks for Simulations A, B, and C are shown in Table 1. Figures 6-7 and 9-10 show the air pollutant concentration levels after passing 30 seconds in contour plot and surface plot between $R=0.007$ (source) and $R=-0.007$ (sink), respectively. Figures 8 and 11 compare the air pollutant concentration levels where $R$ is the constant in first case and second case of Simulation A, respectively. From the results, if we take more source rate into our system, we can see that the concentration of air pollutant levels has increased (see Figure 8). Therefore, the concentration varied with the sources. Furthermore, the sink can lower the concentration of air pollutant levels (see Figure 11). Furthermore, Figures 1213 and 15-16 show the air pollutant concentration levels after passing 30 seconds in contour plot and surface plot between

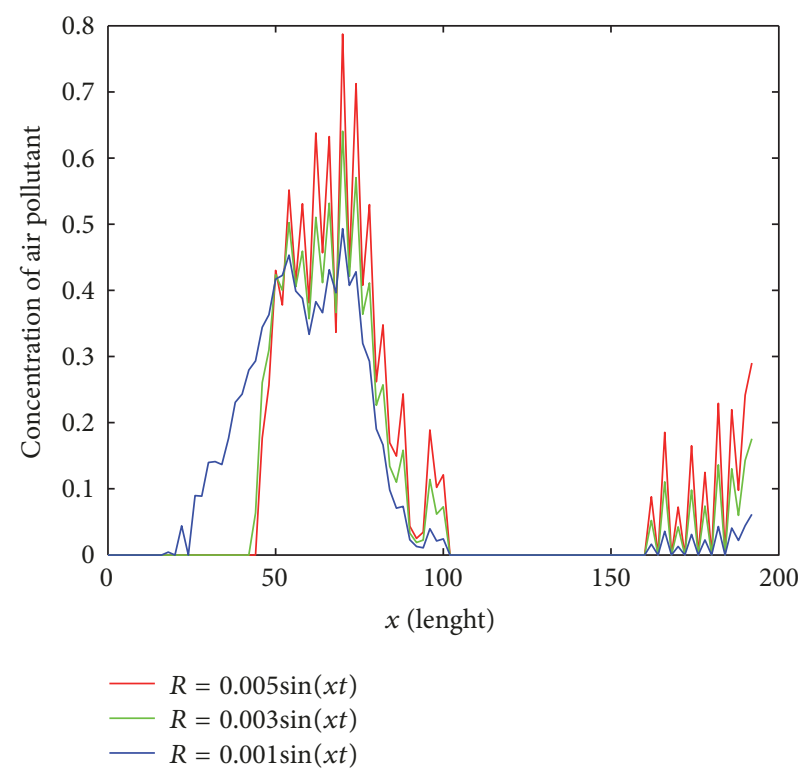

FIgURE 14: Compare the concentration of air pollutant where $R=$ $0.001 \sin (x t), R=0.003 \sin (x t)$, and $R=0.005 \sin (x t) \mathrm{sec}^{-1}$.

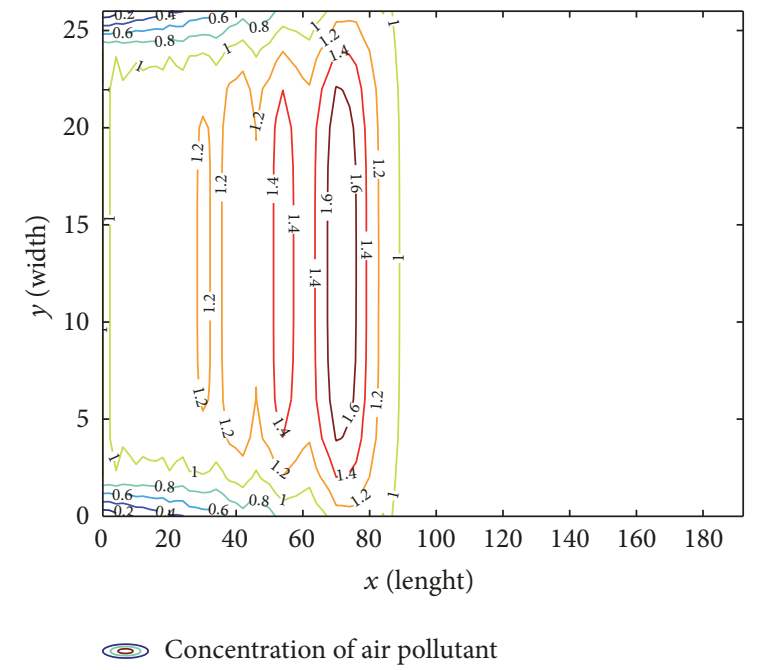

FIGURE 15: Contour plot of concentration of air pollutant levels for $R=0.003|\sin (x t)| \sec ^{-1}$.

$R=0.001 \sin (x t)$ (source-sink) and $R=0.003|\sin (x t)|$ (source), respectively. Figures 14 and 17 compare the air pollutant concentration levels where $R$ is the constant in the first case and second case of Simulation B, respectively. As a result, $R$ is a function of both source and sink and the concentration of air pollutant has increased and decreased (see Figure 14). That is, it is increased when $R$ is the source. On the other hand, if $R$ is sink, the concentration of air pollutant has decreased. Moreover, Figures 18-20 show the air pollutant concentration levels after passing 30 seconds in surface plot where $R$ is the constant in first, second, and third cases of Simulation C, respectively. Figure 21 


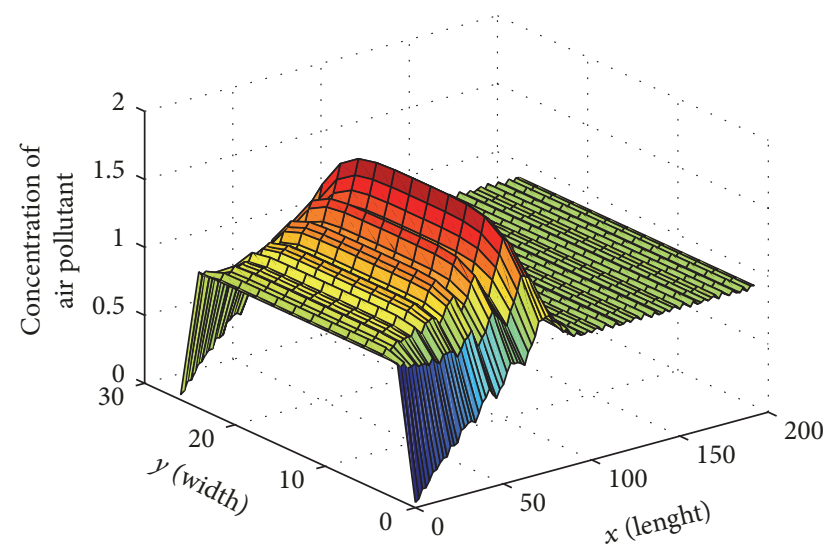

FIgURE 16: Surface plot of concentration of air pollutant levels for $R=0.003|\sin (x t)| \sec ^{-1}$.

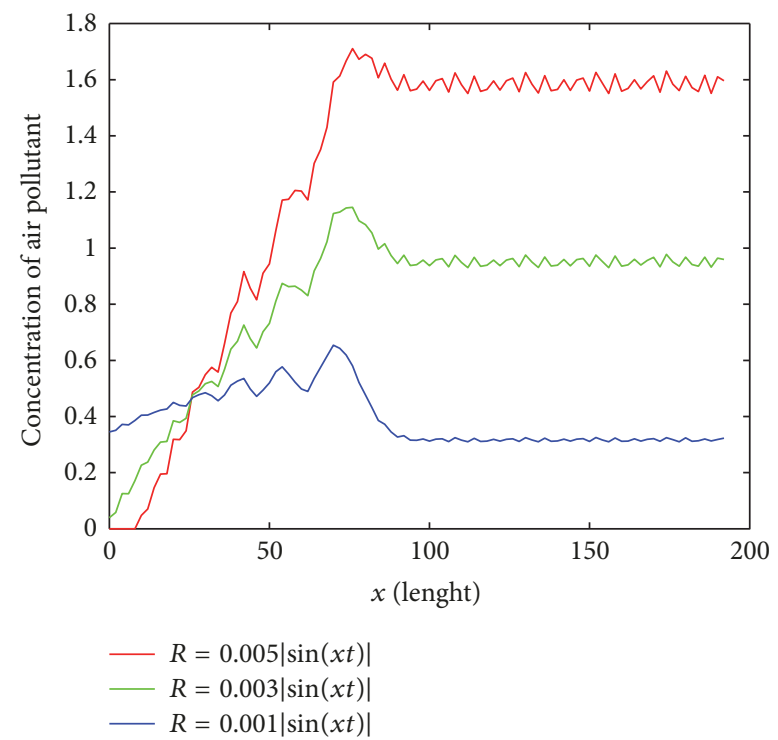

FIGURE 17: Compare the concentration of air pollutant where $R=$ $0.001|\sin (x t)|, R=0.003|\sin (x t)|$, and $R=0.005|\sin (x t)| \mathrm{sec}^{-1}$.

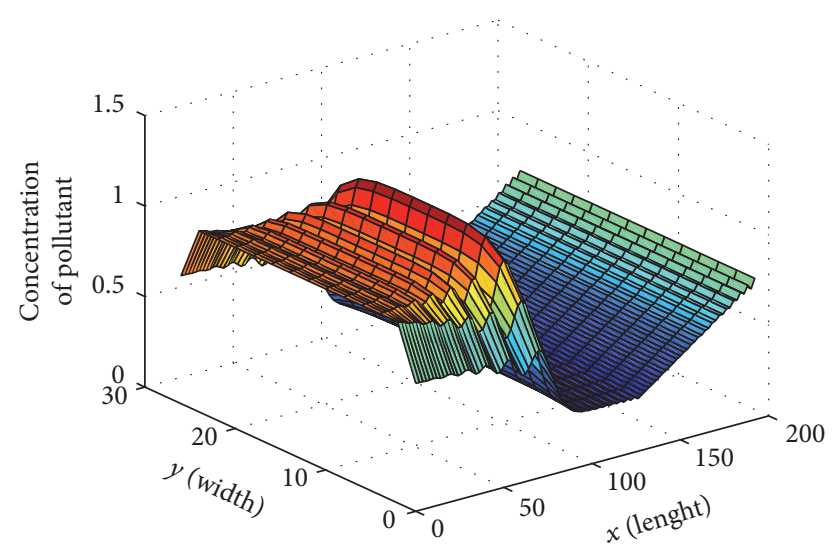

FIGURE 18: Surface plot of concentration of air pollutant levels for $R_{1}=0.01, R_{2}=0.03$, and $R_{3}=0.05 \mathrm{sec}^{-1}$.

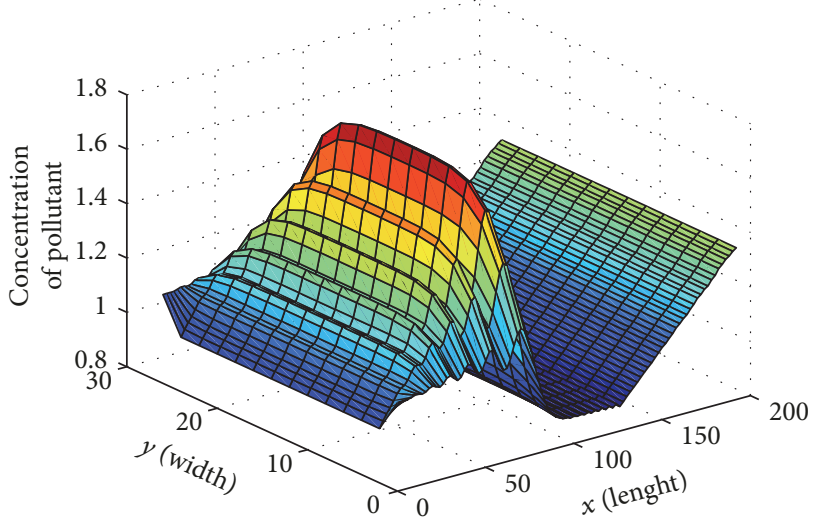

FIGURE 19: Surface plot of concentration of air pollutant levels for $R_{1}=0.03, R_{2}=0.05$, and $R_{3}=0.03 \mathrm{sec}^{-1}$.

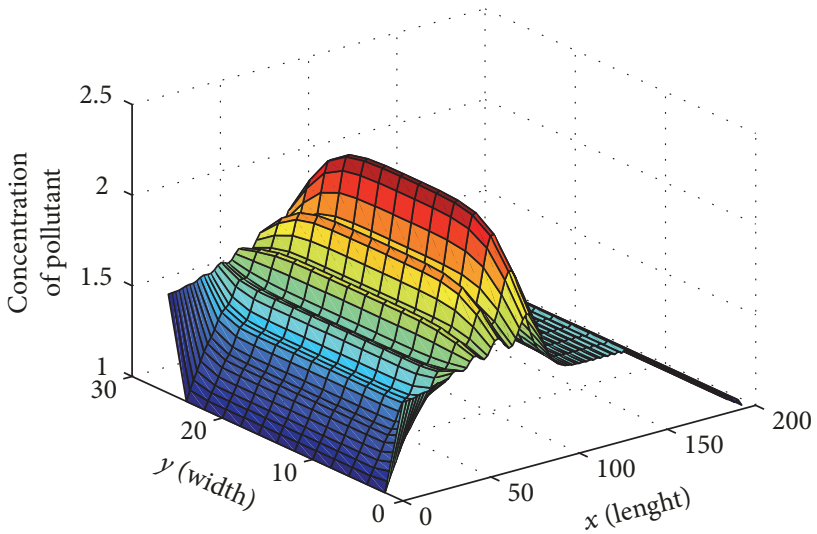

FIGURE 20: Surface plot of concentration of air pollutant levels for $R_{1}=0.05, R_{2}=0.03$, and $R_{3}=0.01 \mathrm{sec}^{-1}$.

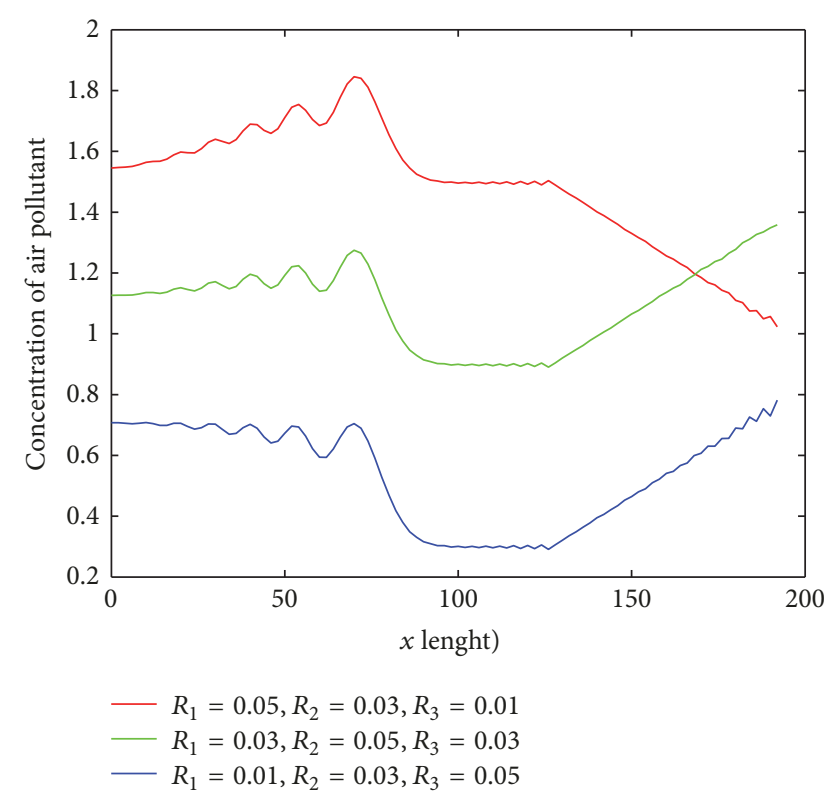

FIgURE 21: Compare the concentration of air pollutant where $R_{1}, R_{2}$, and $R_{3}$ are difference of three cases. 


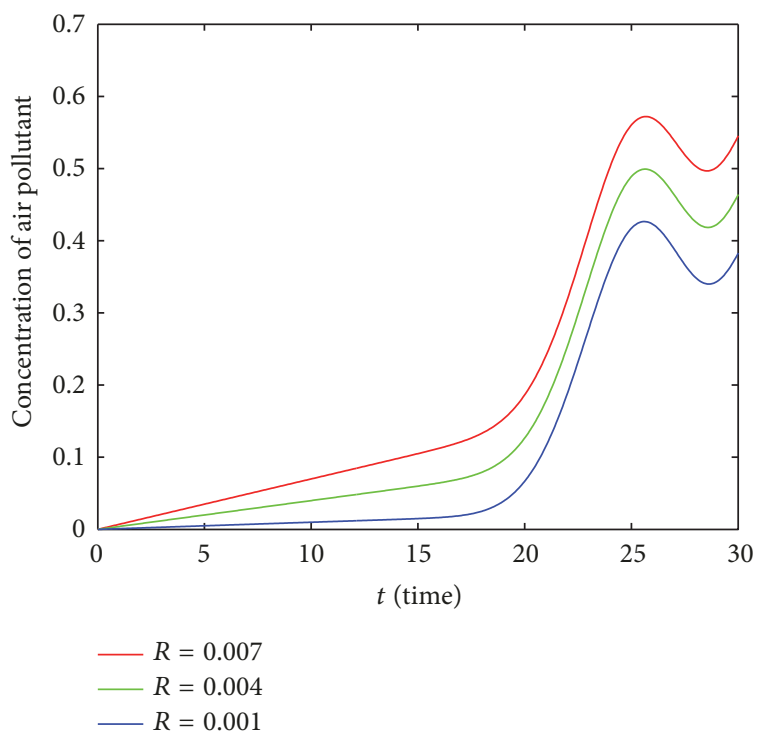

FIGURE 22: Compare the concentration of air pollutant at $x=$ $60 \mathrm{~m}, y=14 \mathrm{~m}, z=4 \mathrm{~m}$ of sources in different time.

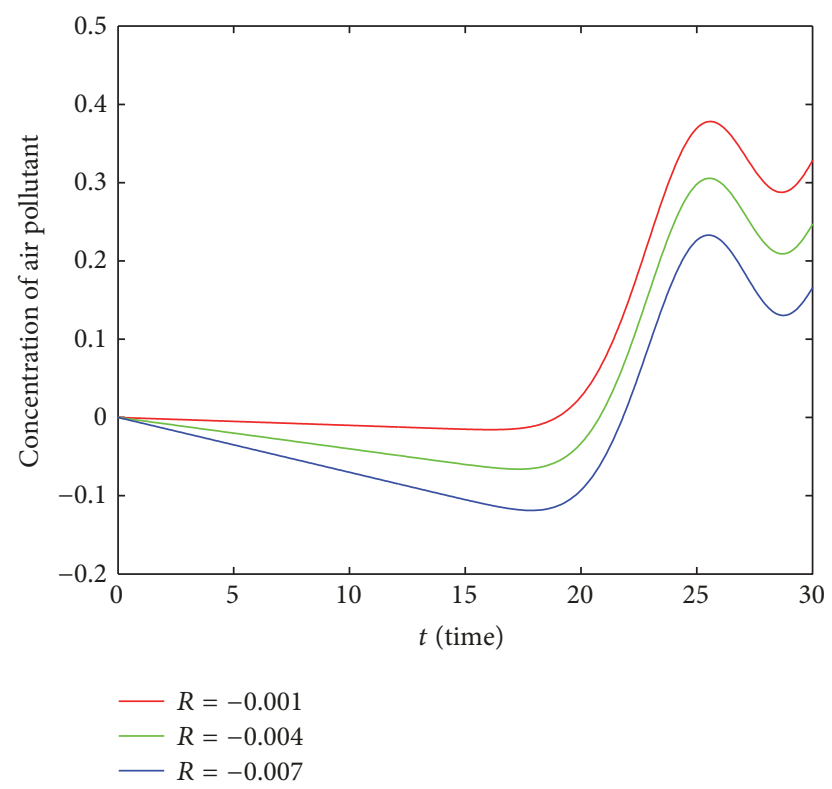

Figure 23: Compare the concentration of air pollutant at $x=$ $60 \mathrm{~m}, y=14 \mathrm{~m}, z=4 \mathrm{~m}$ of sinks in different time.

compares the air pollutant concentration levels of three cases in Simulation C. As a result, it can be concluded that if we add a large quantity of source at the beginning, it affects the concentration of pollutants. Therefore, the source is the cause of high concentration of air pollutant. Moreover, Figures 22-25 compared the concentration of air pollutant at $x=$ $60 \mathrm{~m}, y=14 \mathrm{~m}, z=4 \mathrm{~m}$ in different time of sources, sinks, moving sources (vehicle sources), and 3 averaged zone sources, respectively.

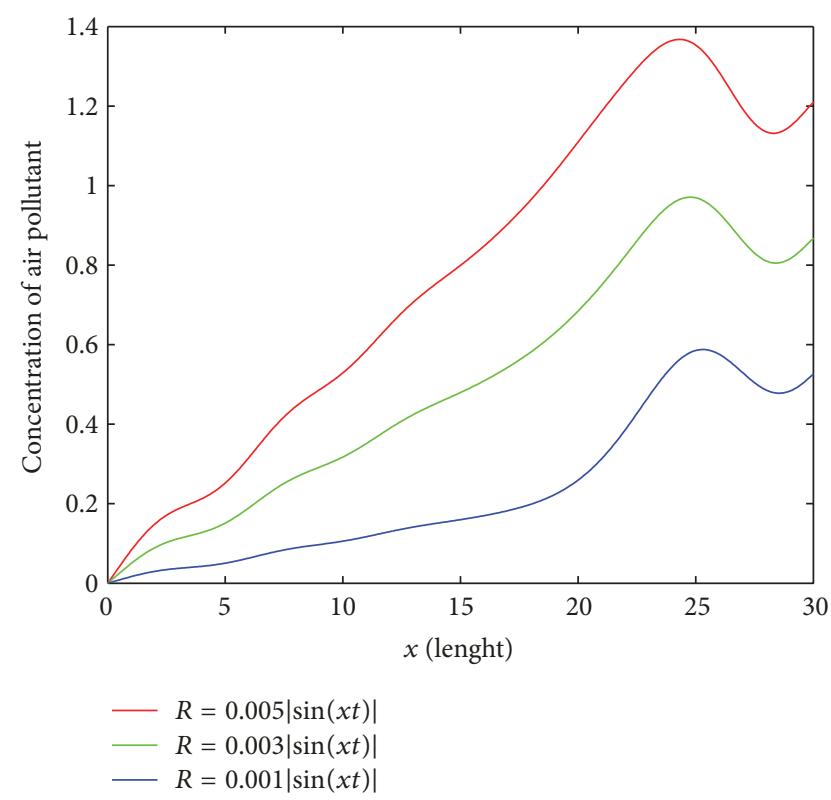

FIGURE 24: Compare the concentration of air pollutant at $x=$ $60 \mathrm{~m}, y=14 \mathrm{~m}, z=4 \mathrm{~m}$ of moving sources (vehicle sources) in different time.

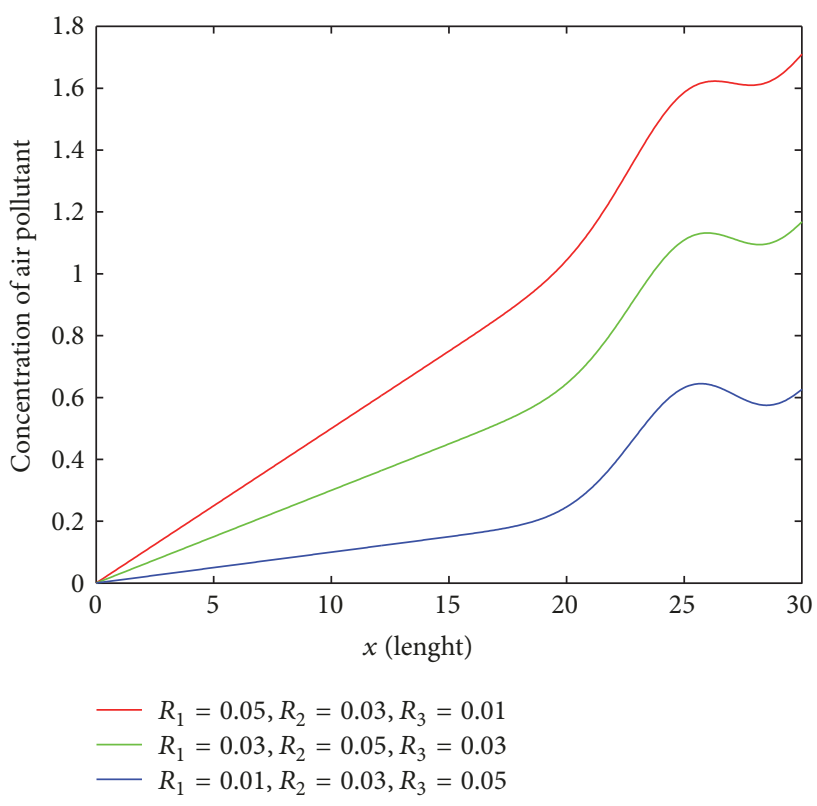

FIGURE 25: Compare the concentration of air pollutant at $x=$ $60 \mathrm{~m}, y=14 \mathrm{~m}, z=4 \mathrm{~m}$ of 3 averaged zone sources in different time.

\section{Conclusion}

The released vehicles air pollutant can be assumed by source functions. The source functions are defined by many methods such as averaged collected data methods or numerical interpolations. The simulations show that the air pollution problems arise by external and internal vehicles that released 
TABLE 1: Comparison of sources or sinks for Simulations A, B, and C.

\begin{tabular}{lccr}
\hline Simulation- & $R_{1}$ & $R_{2}$ & $R_{3}$ \\
Cases & $0 \leq x<64$ & $64 \leq x \leq 128$ & $128<x \leq 192$ \\
\hline A-1.1 & 0.001 & 0.001 & 0.001 \\
A-1.2 & 0.004 & 0.004 & 0.004 \\
A-1.3 & 0.007 & 0.007 & 0.007 \\
A-2.1 & -0.001 & -0.001 & -0.001 \\
A-2.2 & -0.004 & -0.004 & -0.004 \\
A-2.3 & -0.007 & -0.007 & -0.007 \\
B-1.1 & $0.001 \sin (x t)$ & $0.001 \sin (x t)$ & $0.001 \sin (x t)$ \\
B-1.2 & $0.004 \sin (x t)$ & $0.004 \sin (x t)$ & $0.004 \sin (x t)$ \\
B-1.3 & $0.007 \sin (x t)$ & $0.007 \sin (x t)$ & $0.007 \sin (x t)$ \\
B-2.1 & $0.001|\sin (x t)|$ & $0.001|\sin (x t)|$ & $0.001|\sin (x t)|$ \\
B-2.2 & $0.004|\sin (x t)|$ & $0.004|\sin (x t)|$ & $0.004|\sin (x t)|$ \\
B-2.3 & $0.007|\sin (x t)|$ & $0.007|\sin (x t)|$ & $0.007|\sin (x t)|$ \\
C-1 & 0.01 & 0.03 & 0.05 \\
C-2 & 0.03 & 0.05 & 0.03 \\
C-3 & 0.05 & 0.03 & 0.01 \\
\hline
\end{tabular}

air pollution. We can see that, under the platform area, air pollutant level is higher than the outside level due to air flow obstacle.

\section{Conflicts of Interest}

The authors declare no conflicts of interest.

\section{Acknowledgments}

This paper is supported by the Centre of Excellence in Mathematics Program of the Commission on Higher Education (CEM), Thailand.

\section{References}

[1] J. Mackenzie, "Air pollution: Everything you need to know," Natural Resources Defense Council.

[2] R. E. Waller, B. T. Commins, and P. J. Lawther, "Air pollution in road tunnels," British Journal of Industrial Medicine, vol. 18, p. 250, 1961.

[3] S. T. Leong, S. Muttamara, and P. Laortanakul, "Air pollution and traffic measurements in Bangkok streets," Asian J. Energy Environ, vol. 3, pp. 185-213, 2002.

[4] M. Dehghan, "Numerical solution of the three-dimensional advection-diffusion equation," Applied Mathematics and Computation, vol. 150, no. 1, pp. 5-19, 2004.

[5] M. Thongmoon and R. McKibbin, "A comparison of some numerical methods for the advection-diffusion equation," Research Letters in the Information and Mathematical Sciences, vol. 10, pp. 49-62, 2006.

[6] S. A. Konglok and N. Pochai, "Numerical computations of three-dimensional air-quality model with variations on atmospheric stability classes and wind velocities using fractional step method," IAENG International Journal of Applied Mathematics, vol. 46, no. 1, pp. 112-120, 2016.
[7] K. Suebyat and N. Pochat, "A numerical simulation of a threedimensional air quality model in an area under a Bangkok sky train platform using an explicit finite difference scheme," IAENG International Journal of Applied Mathematics, vol. 47, pp. 471-476.

[8] A. C. Hindmarsh and P. M. Gresho, "The stability of explicit Euler time-integration for certain finite difference approximations of the multidimensional advection-diffusion equation," International Journal for Numerical Methods in Fluids, vol. 4, no. 9, pp. 853-897, 1984. 


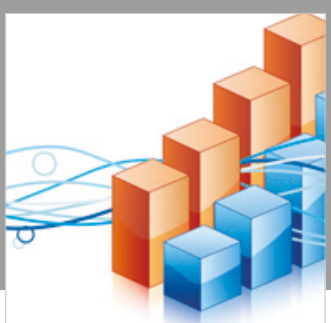

Advances in

Operations Research

\section{-n-m}
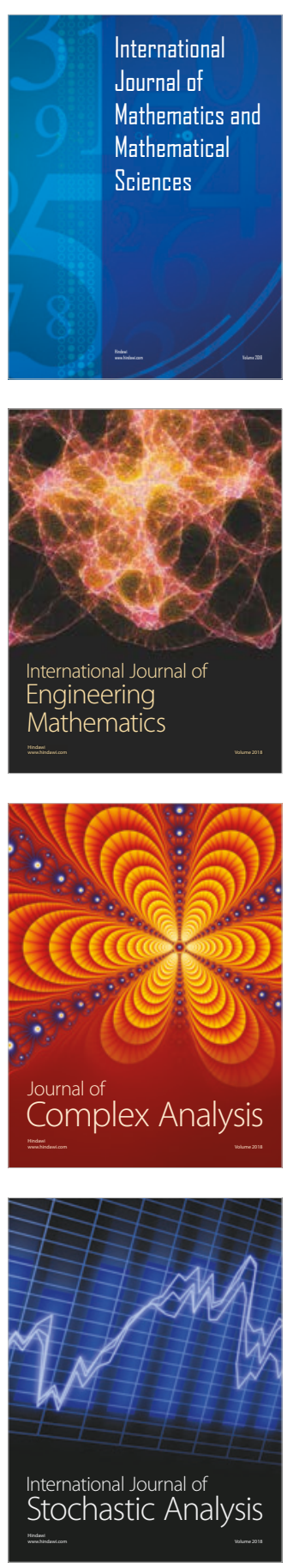
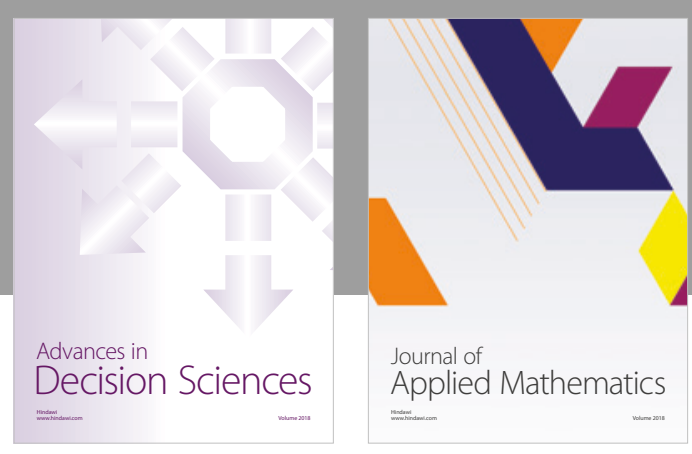

Journal of

Applied Mathematics
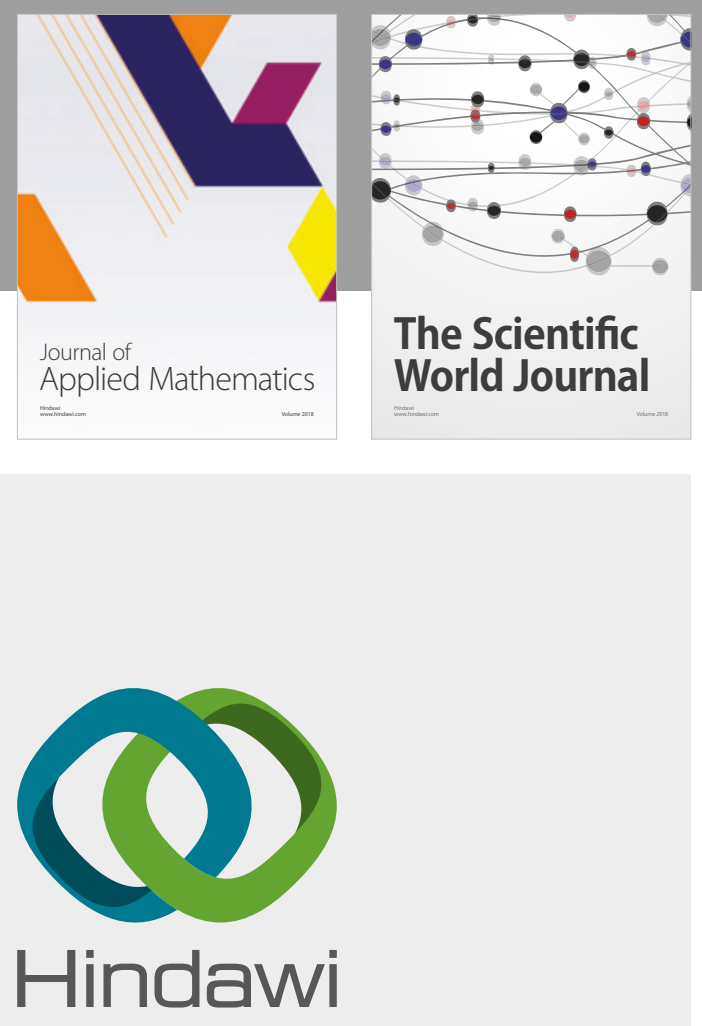

Submit your manuscripts at

www.hindawi.com

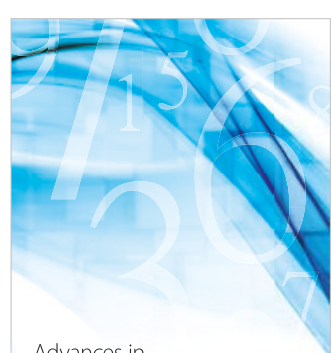

Advances in
Numerical Analysis
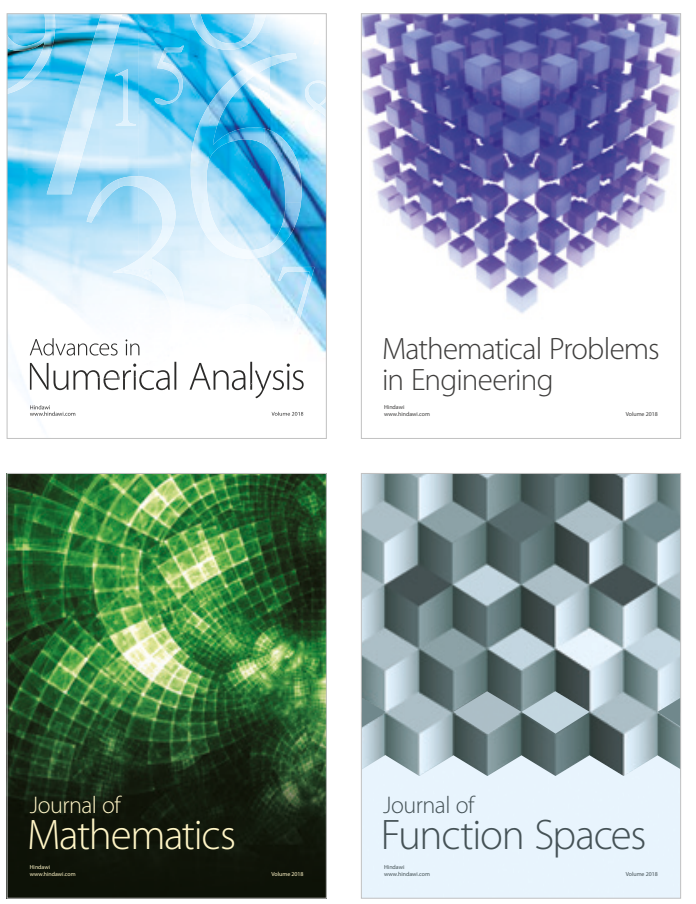

Mathematical Problems in Engineering

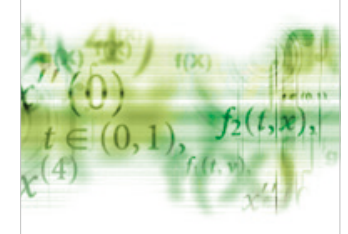

International Journal of

Differential Equations

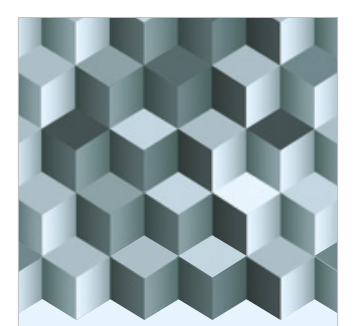

Journal of

Function Spaces

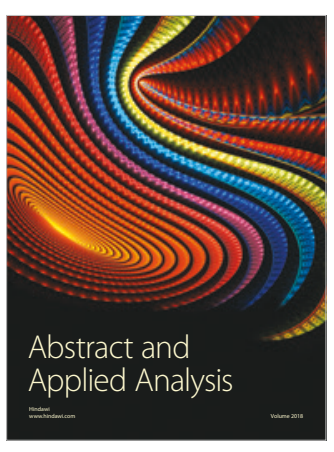

The Scientific

World Journal

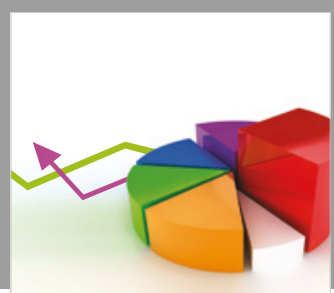

Journal of

Probability and Statistics
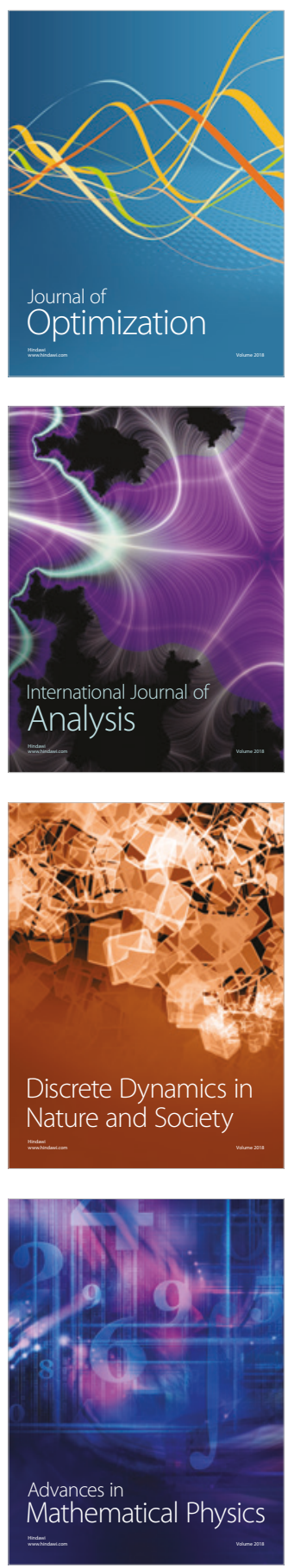